\title{
Graphene gets ready for the big time
}

\section{Physicists are talking about how to make practical use of a former laboratory curiosity.}

\section{PITTSBURGH, PENNSYLVANIA}

Physicists are in the grips of graphene madness. At last week's American Physical Society meeting in Pittsburgh, Pennsylvania, they packed conference rooms to hear about the atom-thick sheets of honeycombed carbon. Talks on graphene transistors, chemical sensors, electrodes, scales and frequency generators could all be heard, with participants from industry, notably IBM, in many of the sessions.

The ultra-thin carbon sheets have turned the normally staid community into "a herd of rhinos", says Andre Geim, a physicist at the University of Manchester, UK. And, he adds, "this year, I feel more like applications are what's driving the field."

Not everyone is sanguine about graphene's chances for going commercial. Graphene has several problems, notably a lack of an obvious 'band gap', a break in electron energy levels that would allow it to be easily used as a transistor, says Kenneth Shepard, an electrical engineer at Columbia University in New York. "There are a lot of problems with this stuff," he warns, fearing that starry-eyed researchers may overhype this latest material.

But others argue that graphene is much more promising than its predecessor, carbon nanotubes. Nanotubes, essentially rolls of graphene, have been difficult to control and integrate into existing electronics, says Tomás Palacios, an electrical engineer at the Massachusetts Institute of Technology in Cambridge. Graphene's uniformity and flatness make it easier to combine with current silicon technology, and many researchers who once worked on nanotubes are now focusing instead on graphene. The shift was evident at this year's meeting: there were 16 sessions on nanotubes, whereas graphene had 28.

Work on graphene - discovered by Geim and his colleagues almost 5 years ago (K. S. Novoselov et al. Science 306, 666-669; 2004) - heated up quickly as researchers realized that the material's two-dimensionality caused it to show unusual quantum behaviours (see Nature 438, 201-204; 2005). But graphene also has properties that make it alluring for certain applications. Electrical charge can fly through the sheets at high velocities, up to four times those in silicon. Large thin layers of graphene would be both flexible and transparent. Graphene ribbons might act as transistors, even though bulk graphene does not. And because graphene is so thin, even the slightest brush from neighbouring atoms can alter its mechanical and electrical properties. "It has been a fascinating material," says Marcus Freitag of IBM's T. J. Watson Research Center in Yorktown Heights, New York.

\section{Silicon transplant?}

To turn graphene applications into reality, the material must first be synthesized in large quantities. Until now, it has often been grown on substrates of silicon carbide, a costly material that is available in only limited quantities from suppliers. But at last week's meeting, several new techniques were on display, including a way to grow graphene through chemical vapour deposition, a process widely used in the electronics industry. In one session, Byung Hee Hong of Sungkyunkwan University in South Korea reported using the technique to grow films up to 10 centimetres in diameter - a figure he soon hopes to double. "There have been great advances in making large-scale graphene," Freitag says.

While some researchers work on making more graphene, others hunt for ways to use it. The most immediate application would be as a simple electrode. Although transparent electrodes using materials such as indium tin oxide are already commercially available, graphene's flexibility would give it an edge in solar cells and displays, says Philip Kim, a physicist at Columbia University.

Graphene also shows promise for broadband communications, in part because electrical charge can move so quickly through it. Graphene transmitters and receivers should be able to operate at frequencies on a scale of hundreds of gigahertz $\left(10^{9} \mathrm{~Hz}\right)$ or even terahertz $\left(10^{12} \mathrm{~Hz}\right)$, far better than silicon, which operates at several gigahertz, says Palacios. Higher

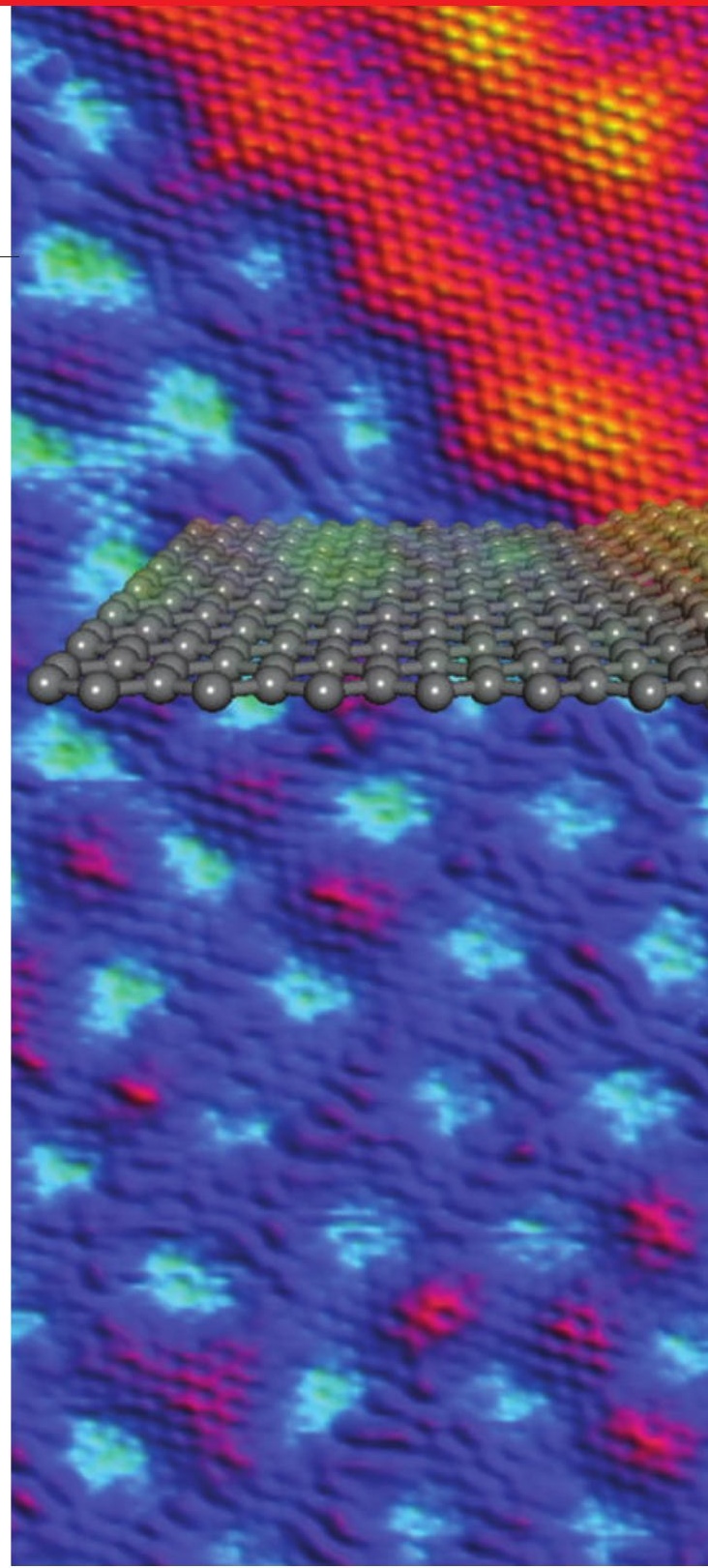

Sheet happens: graphene could have potential uses in solar cells or flexible displays.

frequencies allow for more bandwidth, and that means graphene could pave the way for broadband satellite communication. In early experiments on display at the conference, Han Wang, one of Palacios's graduate students, presented data up to one megahertz $\left(10^{6} \mathrm{~Hz}\right)$, but Palacios is bullish: "We should be able to have competitive devices just a few months from now," he says.

Whether graphene can replace silicon as the basic unit of the electronics industry is another question; its lack of a band gap is a formidable problem. The most obvious solution is to cut the material into ribbons, which have discrete energy levels. But, as several groups showed in Pittsburgh, cutting the sheets creates a jagged edge of dangling chemical bonds that can pick up unwanted contaminants. Xinran Wang of $\frac{\mathrm{u}}{3}$ Stanford University in California reported some success in using ammonia and other compounds to dope the edges of the graphene 


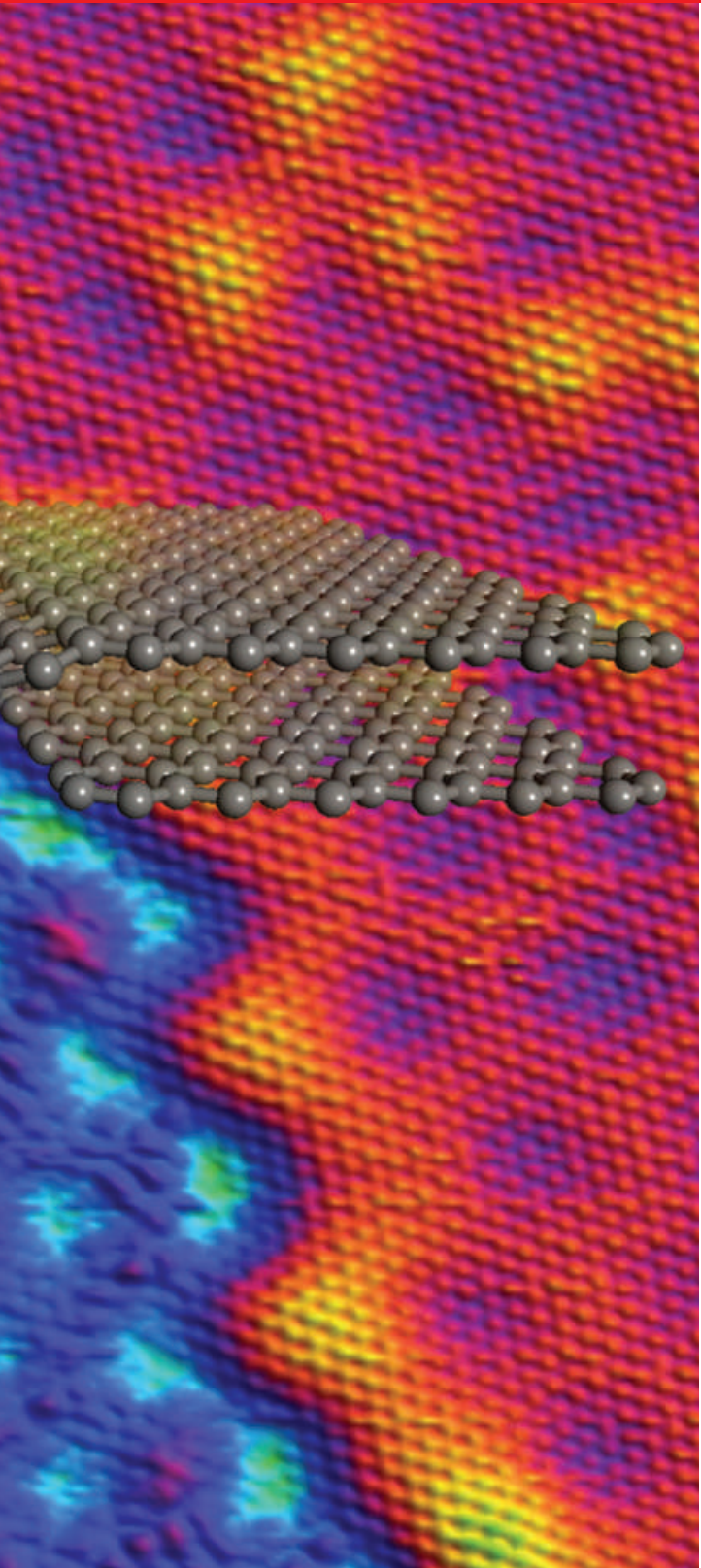

ribbons, allowing them to carry charge more easily. Even then, the scattering of electrons from the ribbon's ragged edges greatly reduces its performance. Based on these kinds of findings, Shepard believes that making these devices work will be extremely difficult. "Nothing's going to supplant silicon, not in my lifetime," he says.

Ultimately, it may be too early to tell just what graphene will - or won't - be able to do. As groups presented models and raw data from their early graphene gadgets, it became clear that many are still grappling with the latest addition to the pantheon of carbon materials. At the end of one talk, Andrea Carlo Ferrari of the University of Cambridge, UK, flashed a few slides onto the screen. Apparently, oxidizing graphene causes it to glow under infrared laser light, Ferrari told the crowd. The data are fresh, and the implications still unclear. "Will this lead somewhere?" Ferrari said afterwards with a shrug, "We don't know."

Geoff Brumfiel

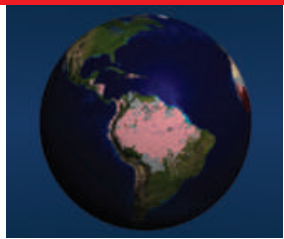

MAPPING MALARIA

Most detailed atlas of disease risk unveiled. www.nature.com/news

\section{UK funding ban sparks protests}

British scientists are campaigning against a plan to bar hundreds of unsuccessful grant applicants from making funding bids in the following year.

The rule, announced by the government's Engineering and Physical Sciences Research Council (EPSRC) on 12 March, aims to reduce the pressure on an overloaded system that currently peer reviews all grant applications.

But by 24 March, more than 1,200 protesters had signed an online petition (http://tinyurl.com/cvyexx) demanding that the policy be repealed. "The feeling in the community is that it is draconian and deeply unfair," says Philip Moriarty, a physicist at the University of Nottingham, UK. He and other scientists contacted by Nature say they will refuse to review their colleagues' work under such a system.

Science-funding experts think that the strategy is unique among UK, US and European funding bodies. "We could not do it in the United States. It would be very contentious," says Antonio Scarpa, director of the Center for Scientific Review at the National Institutes of Health in Bethesda, Maryland. Frank Wissing, life-sciences programme director at Germany's science funding agency, the DFG, adds that its committees have never discussed a ban on unsuccessful applicants.

The EPSRC says that scientists will not be allowed to apply for research funding for 12 months if, in the past 2 years, they have had three or more proposals ranked in the bottom half of a funding prioritization list, and also have less than $25 \%$ of all their proposals funded in that time.

The funding council says it expects 200-250 researchers will be excluded, accounting for $5 \%$ of applicants but $10 \%$ of the total number of applications submitted to the council. Those researchers are "producing a disproportionate load on the peer-review system", says Bill Wakeham, vice-chancellor at the University of Southampton, UK, and a member of the EPSRC council. Excluded scientists will have to undergo a mentoring programme to help improve their success rates before being allowed to submit grants again.

The exclusions will begin from 1 June, and the EPSRC will be contacting the first wave of scientists affected in April, says David Delpy, EPSRC chief executive. "We are a little uncomfortable with something that is applied retrospectively," he says. "But we can't wait another two years to implement it, with success rates falling as they are." Although that rate has hovered around $30 \%$ since 2004, it has dropped to just $24 \%$ in the past year.

Low success rates make applicants more cautious about spending time preparing ambitious proposals, says Delpy, and a flood of safer proposals could crowd out higherrisk but potentially ground-breaking ideas.

Chemists are most likely to be affected by the policy, says David Reid, head of marketing and communications for the EPSRC, because they tend to submit larger numbers of smaller, short-term proposals compared with other subject areas. Some funding areas with a focus on chemistry have seen success rates fall as low as $15 \%$.

"It is the chemists who are mostly complaining, and it is the chemists who produce most of the applications that fail," says Wakeham.

Tom Welton, head of chemistry at Imperial College London, echoed the feeling of many chemists contacted by Nature, calling the move a "kneejerk bureaucratic response". "We are appalled by the lack of consultation," adds Joe Sweeney, an organic chemist at the University of Reading, UK.

Reid concedes that the EPSRC did not consult widely on the specifics ut he argues that a 2007 consultation by Research Councils UK, an umbrella group for the country's research funding councils, had found that some academics supported the idea of targeted disincentives to improve success rates.

Delpy says that other options considered by the council, but rejected, included charging for submissions; applying institutional quotas; or penalizing universities by making doctoral training grants proportional to their success rates.

Along with the exclusion policy, which will be reviewed in a year's time, the EPSRC will also refuse uninvited resubmissions of failed proposals, bringing it in line with other UK research councils.

Richard Van Noorden

See Editorial, page 385 . 